\title{
Nationalist character at Muhammadiyah school
}

\section{Syifa Siti Aulia ${ }^{1}$, Dikdik Baehaqi Arif ${ }^{2}$, Idham Sofihara ${ }^{3}$, Astika Pungki Utami ${ }^{4}$, Laelaturrohmah ${ }^{5}$, Iqbal Arpannudin 6}

1,2,3,4,5 PPKn Study Program, Universitas Ahmad Dahlan, Yogyakarta Indonesia

${ }^{6}$ PPKn Study Program, Universitas Negeri Yogyakarta, Yogyakarta Indonesia

\section{ABSTRACT}

One of the ways to strengthen nationalist character values is through formal education, including in Muhammadiyah schools. The practice needs strengthening in Muhammadiyah schools for deviations in student behavior that do not reflect the values of nationalist character. This article attempts to provide an overview of strengthening the values of nationalist characters through Muhammadiyah school culture. The research method used is qualitative research. The focus of the object in this study is strengthening the value of nationalist character for students in Muhammadiyah schools. The steps of data analysis using data reduction models, data presentation, conclusions. The study results show that there are several school programs to instill the values of nationalist character through school culture, among others, through learning in the classroom and habituation outside the classroom, among others, through extracurricular activities. The supporting factor is that the school establishes with the parties to run the program. The inhibiting factor is that some students are still not optimal in participating in a school program.
\end{abstract}

\section{Article History: \\ Submitted : :04-03-2021 \\ Revised : :25-03-2021 \\ Accepted : 26-03-2021}

Keywords:

character, civic education,

Muhammadiyah school, nationalist

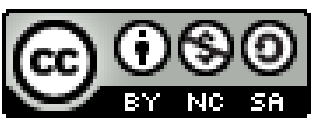

Cite in APA ${ }^{\text {7th: }}$

Aulia, S. S., Arif, D. B., Sofihara, I., Utami, A.P., Laelaturrohmah \& Arpannudin, I. (2021). Nationalist character at Muhammadiyah school. Jurnal Civics: Media Kajian Kewarganegaraan, 18(1) 172-178. https://doi.org/10.21831/jc.v18i1.39183

\section{Pendahuluan}

Bangsa yang besar adalah bangsa yang memperhatikan dan selalu menanamkan jiwa nasionalis kepada warga negaranya. Nilai tersebut terus dikuatkan terutama kepada generasi muda di Indonesia agar karakter terus berjalan dan diimplementasikan secara berkelanjutan. Nilai karakter nasionalis terdiri dari menjaga dan mengapresiasi budaya bangsa, menghormati keberagaman, unggul dan berprestasi, cinta tanah air, menjaga lingkungan, disiplin dalam taat aturan (Kementerian Pendidikan dan Kebudayaan, 2017).

Negara Indonesia yang berbentuk kepulauan dengan karakter budaya yang berbeda ini memerlukan kekuatan untuk membentuk nilai karakter nasionalis tersebut, bahkan ketika Indonesia tengah dihadapkan dengan arus globalisasi maka Indonesia perlu teknik dalam penguatan nasionalisme, hal ini dinamakan dengan revitalisasi penguatan nasionalisme untuk memperkuat daya saing bangsa (Sulistiyono, 2018).

Penguatan nasionalisme yang dilakukan tersebut dapat dikatakan belum maksimal atau belum diterima dengan baik secara menyeluruh oleh masyarakat. Beberapa aksi teror bermunculan di Negara Indonesia bahkan beberapa bermunculan mengatasnamakan agama. Sehingga agama seolah di kambinghitamkan atas segala masalah yang terjadi berkaitan dengan aksi teror yang dianggap melemahkan rasa nasionalis. Anggapan tersebut muncul di dalam maupun luar negeri padahal pelaku hanya sebuah oknum atau kelompok bukan secara menyeluruh umat Islam. Sejatinya Islam adalah 
agama yang cinta kedamaian. Selama lebih dari sepuluh tahun, pilar demokrasi Indonesia (negara), polisi, dan masyarakat sipil Muslim belum mampu menghentikan serangan (Menchik, 2014).

Organisasi keagamaan merupakan alah satu yang memiliki peran dari organisasi masyarakat keagamaan untuk menangkal oknum yang dinamai radikal terutama yang mengatasnamakan agama. Pengertian radikalisme menurut Zakiyah (Ali et al., 2018, pp. 106-107) menjelaskan sebagai "gerakan semangat keagamaan yang bertujuan mengubah sebuah tatanan politik atau tatanan sosial dengan taktik kekerasan. Organisasi masyarakat mampu menjadi kontrol sosial mengenai pola-pola yang terjadi di masyarakat jika terjadi penyimpangan-penyimpangan". Organisasi keagamaan bersama pemerintah aparat keamanan menyelenggarakan penyuluhan atau sosialisasi dalam bentuk pengajian, kegiatan ibadah, kepada warga Bekasi dalam upaya mencegah Radikalisme (Ali et al., 2018). Ada banyak organisasi masayarakat dalam keagamaan yang muncul Indonesia, dua organisasi besarnya adalah Nahdhatul Ulama dan Muhammadiyah. Kedua organisasi tersebut dicetuskan dua tokoh ternama dan berpengaruh yang mengajarkan rasa cinta terhadap tanah air. Masyarakat Muslim Indonesia berakar pada Nahdlatul Ulama (NU) dan Muhammadiyah, yang bersama-sama mengelola ribuan sekolah dan universitas, ratusan rumah sakit dan klinik, organisasi pemuda, masjid, lingkaran doa, partai politik, dan sayap perempuan, dan memilih pemimpin di tingkat nasional, provinsi, kabupaten, desa, dan lingkungan (Mujani \& Liddle, 2004).

Organisasi Muhammadiyah memiliki peran guna menjaga dan merawat karakter nasionalis. Mengingat Muhammadiyah merupakan organisasi Islam besar sehingga pengaruhnya cukup besar di Indonesia. Melihat pendapat Asmaria \& Ponirin (2013) sebagai bahwa "untuk mencapai maksud dan tujuan Muhammadiyah yaitu dengan melaksanakan Dakwah Amar Makruf Nahi Munkar yang diwujudkan dalam usaha di bidang agama, pendidikan, sosial dan ekonomi." Organisasi ini sadar dalam membentuk karakter bangsa dapat dimunculkan melalui amal usahanya di bidang pendidikan. Organisasi Islam atas pemikiran KH. Ahmad Dahlan ini yang ingin Islam pembaharuan sampai sekarang berkembang sangat pesat seperti banyaknya pondok pesantren, sekolah, dan perguruan tinggi tersebar di Indonesia.

Selain dari organisasi masyarakat, usaha pemerintah untuk menanamkan karakter kepada masyarakat salah satunya melalui dikeluarkannya Permendikbud No 20 tahun 2018 tentang Penguatan Pendidikan Karakter (PPK) pada satuan pendidikan formal. Di dalamnya terdapat penguatan karakter nasionalis dengan mengoptimalkan fungsi kemitraan tri pusat pendidikan salah satunya melalui sekolah yakni melalui budaya sekolah. Sikap nasionalis dapat ditunjukkan melalui sikap apresiasi terhadap budaya bangsa sendiri, cinta tanah air, menjaga lingkungan, taat hukum, menghormati keragaman budaya, suku, dan agama. Dalam proses pembentukan karakter dapat dilakukan dengan pembiasaan di dalam sekolah. Pembiasaan yang berlangsung lama tersebut akan menjadi budaya di sekolah tersebut. Budaya tersebut merupakan nilai-nilai positif yang berkembang dan terus dilestarikan oleh warga sekolah baik kepala sekolah, guru, maupun peserta didik.

Untuk itu perlu adanya peran yang dilakukan pihak sekolah sebagai wadah dalam rangka penguatan nilai karakter nasionalis (Permendikbud, 2018). Pendidikan merupakan salah satu cara ampuh untuk menguatkan nilai karakter nasionalis suatu bangsa. Begitupun penguatan karakter nasionalis berlaku di sekolah Muhammadiyah, melalui sekolah Muhammadiyah dapat menjadi sarana dakwah bidang pendidikan yang terdapat nilai kebangsaan dan diajarkan nilai Islami sesuai Al-Quran dan As-sunah. Amal usaha pendidikan Muhammadiyah tidak hanya terfokus pada pembelajaran ilmuilmu umum maupun ilmu agama saja namun juga membentuk karakter berakhlak mulia dan cinta tanah air. Hal ini juga sejalan dengan yang dipaparkan dalam Permendikbud mengenai penguatan pendidikan karakter. Sehingga adanya penguatan seperti ini dapat melahirkan kader-kader bertakwa, berakhlak, intelektual, dan nasionalis sehingga bermanfaat bagi kemaslahatan umat. 
Di Kota Yogyakarta merupakan lahirnya dan pusat berkembangnya organisasi Muhammadiyah. Hal ini dapat dilihat dari bidang yang paling menonjol adalah pendidikan, dimana tersebar banyak sekolah Muhammadiyah dan terdapat beberapa perguruan tinggi Muhammadiyah. Adanya kontribusi dalam pembentukan karakter nasionalis yang dapat ditanamkan melalui budaya sekolah. Mendasari hal di atas, maka dalam artikel ini akan mengungkapkan hal apa saja yang dapat dilakukan oleh sekolah Muhammadiyah untuk menguatkan karakter nasionalis.

\section{Metode}

Artikel ini merupakan hasil dari sebuah penelitian. Metode penelitian yang digunakan adalah melalui metode penelitian kualitatif didasarkan pada kajian penelitian yang berupaya untuk memberikan gambaran mengenai budaya sekolah muhammadiyah dalam proses pendidikan karakter khususnya mengenai nilai karakter nasionalis pada peserta didik. Provinsi Yogyakarta diambil sebagai tempat penelitian didasarkan pada alasan bahwa Yogyakarta merupakan pusat berkembangnya organisasi Muhammadiyah dengan banyaknya lembaga pendidikan di dalamnya.

Metode penelitian dilakukan diawali dengan proses wawancara dan dokumentasi dari salah satu pengambil kebijakan di sekolah muhammadiyah yakni sekretaris majelis pendidikan dasar dan menengah pimpinan wilayah muhammadiyah Daerah Istimewa Yogyakarta (Majelis Dikdasmen PWM DIY). Hasil dari wawancara dan dokumentasi tersebut, dilakukan triangulasi data dengan mencari data lainnya di beberapa tempat penelitian dengan mengambil subjek yakni kepala sekolah, guru, dan siswa. Data dari 3 subjek tersebut didapatkan menggunakan teknik wawancara, dokumentasi, dan observasi di beberapa sekolah Muhammadiyah yakni SMP Muhammadiyah 2 Yogyakarta, SMA Muhammadiyah 2 Yogyakarta, dan SMK Muhammadiyah 3 Yogyakarta. 3 Sekolah tersebut dipilih didasarkan data sebagai sekolah yang memiliki peminat peserta didik yang banyak.

Pelaksanaan reduksi data di lakukan selama penelitian berlangsung di 4 tempat tersebut yakni data di pengambil kebijakan sekolah yakni majelis Dikdasmen PWM DIY dan 3 sekolah yang dipilih sebagai Triangulasi data lapangan untuk validitas data kualitatif yang didapatkan. Data kemudian dianalisis dan disimpulkan dengan membandingkan semua teknik penelitian yang digunakan yakni wawancara, dokumentasi, dan observasi dari berbagai subjek penelitian terutama Pemegang kebijakan (Majelis Dikdasmen PWM DIY) dan pelaksana aktivitas di persekolahan (Kepala Sekolah, Guru, dan Peserta Didik). Kelemahan dari penelitian ini adalah observasi yang tidak maksimal dikarenakan proses pembelajaran daring di masa pandemi.

\section{Hasil dan Pembahasan}

Dari data hasil penelitian didapatkan bahwa sekolah-sekolah Muhammadiyah memiliki berberapa program untuk menanamkan nilai karakter nasionalis, melalui ekstra kurikuler Tapak Suci, Hizbul Wathan, dan organisasi intra sekolah berupa Ikatan Pelajar Muhammadiyah. Selain itu, sekolah melakukan internalisasi dengan memasukan kegiatan tersebut ke dalam RKAS (Rencana Kegiatan dan Anggaran Sekolah).

Penguatan yang dilakukan oleh sekolah Muhammadiyah yakni berbentuk kegiatan ISMUBA (Islam, Muhammadiyah, dan Bahasa Arab) merupakan pembelajaran yang harus di tekuni oleh setiap pelajar muhammadiyah. Berdasarkan hasil data lapangan ditemukan bahwa Kegiatan ISMUBA juga dilaksanakan bukan hanya dalam ranah kognitif, tapi juga afektif dan psikomotorik. Kegiatan ISMUBA ini memungkinan memperkuat karakter nasionalis dari peserta didik dengan memahami nilai agama sebagai pancaran dari implementasi sila pertama yakni Ketuhanan Yang Maha Esa. Ketika kegiatan ISMUBA ini terimplementasi dalam koridor kognitif, afektif, dan psikomotorik seperti yang dikemukakan oleh Sekretaris Majelis Dikdasmen PWM DIY, maka konseptual kaitan dengan 
pengintegrasian antara ke-Islam-an dan Ke-Indonesiaan akan terwujud dan mudah terlaksana (Arif \& Aulia, 2017).

Berdasarkan Wawancara dengan salah satu pengurus Majelis Dikdasmen PWM DIY ditemukan data bahwa Nilai-nilai Kemuhammadiyahan dan nilai nasionalisme dapat diwujudkan melalui kegiatan Hizbul Wathon, Ikatan Pelajar Muhammadiyah (IPM) dan Tapak Suci. Ketiga Kegiatan yang berada di sekolah-sekolah Muhammadiyah menggambarkan bahwa proses pembelajaran holistik integratif terjadi. Pembelajaran holistik-integratif menurut John Dewey adalah pendekatan untuk mengembangkan pengetahuan peserta didik didasarkan pada interaksi dan pengalaman hidup dari peserta didik (Hijriyani \& Machali, 2017). Berdasarkan data dalam penelitian di sekolah-sekolah Muhammadiyah ditemukan data berkaitan dengan pola sekolah dalam mengintegrasikan proses pembelajaran tentang karakter nasionalis ini terbentuk tidak hanya aktifitas belajar di dalam kelas namun sampai di kegiatan di luar kelas.

SMA Muhammadiyah 2 Yogyakarta sebagai salah satu sekolah Muhammadiyah menggambarkan tentang sikap nasionalis yang dapat terwujud di sekolah salah satunya adalah berkaitan dengan sikap apresiasi terhadap budaya bangsa sendiri Hal ini telah diterapkan di SMA Muhammadiyah 2 dilihat interaksi di dalam sekolah, selain menggunakan bahasa Indonesia sebagai bahasa sehari-hari tidak sedikit warga sekolah menggunakan Bahasa Jawa kromo inggil dilakukan sebagai wujud menghormati orang yang lebih tua (penerapan salam, sapa, senyum, sopan, santun). Beberapa program sekolah lainya yakni pertukaran pelajar internasional yang dapat mengenalkan budaya Indonesia terhadap negara luar negeri; diajarkannya melalui ekstrakurikuler kegiatan hizbul wathan kepanduan dibawah organisasi Muhammadiyah, tapak suci sebagai seni bela diri milik Indonesia dibawah nangan Muhammadiyah, tari dengan mempelajari tarian daerah di Indonesia yang biasanya ditampilkan ketika pensi dengan tema kebudayaan; pameran budaya berupa alat tradisonal dan benda sejarah serta kebiasaan menggunakan pakaian jawa setiap hari kamis pahing sebagai wujud mencintai budaya yang bangsa sendiri.

Gambaran sikap apresiasi terhadap budaya bangsa Indonesia yang ditampilkan di salah satu sekolah Muhammadiyah tersebut menggambarkan bahwa karakter nasionalis dapat dibentuk melalui proses pembiasaan dalam kegiatan sekolah yang terintegrasi melalui berbagai macam kegiatan yang terpola dengan baik, salah satunya yakni ditanamkan identitas bangsa dan negara dalam kehidupanya, dengan demikian akan muncul pribadi-pribadi yang cinta dan bangga akan bangsanya (Attaran, 2015; Lisnawati, 2016). Berbagai macam program sekolah di SMA Muhammadiyah 2 Yogyakarta khususnya berkaitan dengan pembentukan karakter nasionalis memberikan gambaran secara tidak langsung bahwa penerapan pengetahuan, nilai, dan keterampilan ditampilkan dalam situasi kehidupan nyata peserta didik untuk berpartisipasi aktif dalam program-program sekolah (Doğanay, 2012) Peran Pendidikan kewarganegaraan secara substantif di lingkungan Budaya sekolah Muhammadiyah terbentuk bahwa sekolah Muhammadiyah tidak saja mendidik generasi muda menjadi warga negara yang cerdas dan sadar akan hak dan kewajibannya dalam konteks kehidupan bermasyarakat, berbangsa, dan bernegara, melainkan juga membangun kesiapan warga negara untuk menjadi warga dunia (global society).

Berdasarkan data lapangan di SMP Muhammadiyah 2 Yogyakarta terungkapkan bahwa sekolah tersebut memiliki kegiatan rutin, kegiatan terprogram dan kegiatan spontan yang menggambarkan penguatan karakter nasionalis di sekolah tersebut. Hanya bentuk kegiatan terprogram yang tersusun dalam rencana kegiatan dan anggaran sekolah yang dilaporkan ke Dikdasmen Muhammadiyah. Bentuk kegiatan rutin seperti upacara bendera dan menyanyikan lagu kebangsaan indonesia raya setiap pagi dipandu oleh staf yang bertugas dari ruang informasi merupakan gambaran dari kegiatan rutin dalam penguatan karakter nasionalis sekolah Muhammadiyah. Pembiasaan upacara bendera tentunya sebagai salah satu aktivitas yang relevan dalam penguatan nasionalis (Salminati, 2017). 
Kegiatan terprogram dalam penguatan karakter nasionalis dimunculkan di SMP Muhammadiyah 2 Yogyakarta yakni memakai pakaian adat kebaya/lurik setiap hari kamis pahing sebagai wujud mencintai budaya berupa pakaian adat, kegiatan pemilihan pengurus IPM (Ikatan Pelajar Muhammadiyah) dan Ortom (Organisasi Otonom) sebagai bentuk kegiatan politik peserta didik dalam berorganisasi. Memakai pakaian adat sebagai bentuk dari memahami nasionalisme sebagaimana terukapkan oleh Tilaar (2007) bahwa nasionalisme itu dapat terwujus dengan mengekspresikan budaya yang ada sebagai bentuk faktor objektif yang membedakan dengan bangsa yang lain.

Kegiatan spontan yang dilakukan di SMP Muhammadiyah 2 Yogyakarta yakni tradisi yang biasa dilaksanakan berupa kegiatan bakti sosial yang sesuai dengan kegiatan amal usaha Muhammadiyah yaitu Meningkatkan semangat ibadah, jihad, zakat, Infak, Wakaf, Shodaqoh, hibah, dan amal shalih lainnya. Kegiatan terprogram yang di munculkan di salah satu sekolah Muhammadiyah tersebut menguatkan posisi peserta didik untuk mendalami nilai nasionalis dengan wujud empati. Kegiatan bakti sosial yang terprogram di sekolah Muhammadiyah menjadi wujud empati dari peserta didik dan hal tersebut dapat menguatkan nasionalis (Abhilasha-R, 2018).

Temuan di SMK Muhammadiyah 3 Yogyakarta tentang penguatan karakter nasionalis peserta didik ditemukan bahwa Pembiasaan nilai-nilai di sekolah untuk menciptakan sikap demokratis tercermin dari dalam kegiatan organisasi yang diikuti peserta didik dimana mereka diberikan wadah mengembangkan minat bakat sembari melatih kemampuan berdiskusi untuk menentukan keputusan tertentu seperti pemilihan ketua. Pembiasaan nilai-nilai di sekolah untuk menghormati keragaman suku, agama, dan budaya tercermin darisikap saling menghargai dan saling bekerja sama dengan teman di dalam maupun luar lingkungan sekolah serta kegiatan bakti sosial dalam menolong orang yang membutuhkan tanpa melihat latar belakangnya. Sekolah telah memberikan ruang untuk peserta didik melalui ekstrakurikuler dalam meningkatkan rasa cinta tanah air dengan kegiatan yang berkaitan cinta tanah air yang bersifat wajib diikuti seperti Hisbul Wathan (HW).

Berdasarkan seluruah temuan di lapangan dapat diuraikan bahwa sekolah Muhammadiyah memiliki aktifitas dan/atau program sekolah yang seluruhnya menggambarkan penguatan karakter nasionalis. Secara Umum kegiatan yang keseluruhan sebagai budaya sekolah Muhammadiyah yang menggambarkan karakter nasionalis adalah kaitannya dengan kegiatan upacara bendera, ekstrakulikuler HW, dan keaktifan peserta didik di Ikatan Pelajar Muhammadiyah (IPM). Ada kegiatankegiatan lain di sekolah Muhammadiyah yang sifatnya insidental menyesuaikan kekuatan dan kebutuhan sekolah dalam penguatan nasionalis. Faktor penghambat yang muncul dalam penguatan karakter nasionalis di sekolah adalah berkaitan dengan faktor lingkungan siswa yang memiliki kecenderungan kuat untuk mempengaruhi sikap peserta didik sehingga sekolah perlu berupaya untuk menguatkan kegiatan ekstrakulikuler yang berada di sekolah Muhammadiyah hal ini pun perlu dikuatkan dengan keberadaan pengambil kebijakan rencana kerja sekolah yakni Majelis Dikdasmen Muhammadiyah.

\section{Simpulan}

Terdapat beberapa program sekolah Muhammadiyah untuk menanamkan nilai karakter nasionalis yang kemudian terimplementasi dalam budaya sekolah antara lain melalui pembelajaran di dalam kelas, dan pembiasaan di luar kelas yakni melalui ekstrakurikuler. Faktor pendukungnya sekolah menjalin dengan berbagai pihak guna menjalankan program yang kaitannya sebagai penguat pembentukan karakter nasionalis. Faktor penghambatnya masih terdapat beberapa peserta didik yang belum maksimal dalam mengikuti suatu program sekolah dalam pembentukan karekter nasionalis dikarenakan pengaruh di luar sekolah yang begitu kuat untuk membentuk karakter peserta didik. 


\section{Ucapan Terima Kasih}

Terima Kasih kepada Majelis Dikdasmen PWM DIY beserta dengan sekolah-sekolah Muhammadiyah di Yogyakarta yang telah memberikan kesempatan untuk melakukan kajian di lingkungan tersebut. Dan terima kasih kepada Universitas Ahmad Dahlan yang telah memberikan bantuan finansial untuk melaksanakan penelitian dengan No Kontrak Penelitian Nomor: PJB021/SP3/LPPM-UAD/VI/2020

\section{Referensi}

Abhilasha-R. (2018). Revoking the spirit of nationalism and empathy through social media: A case study of siachen tragedy. International Journal of Creative Research Thoughts (IJCRT), 6(1), 1133-1136.

Ali, Y., Sukendro, A., Sarjito, A., \& Saragih, H. . (2018). Peran organisasi keagamaan dalam mencegah radikalisme di wilayah Kota Bekasi. Manajemen Pertahanan, 4(2), 104-119. http://jurnalprodi.idu.ac.id/index.php/MP/article/view/311

Arif, D. B., \& Aulia, S. S. (2017). Studi tentang "negara Pancasila sebagai darul ahdi wa syahadah" untuk penguatan materi pembelajaran Pendidikan Kewarganegaraan di Universitas Ahmad Dahlan. Jurnal Civics: Media Kajian Kewarganegaraan, 14(2), 206-217. https://doi.org/10.21831/civics.v14i2.16440

Asmaria, I., \& Ponirin. (2013). Perkembangan amal usaha organisasi Muhammadiyah di bidang pendidikan dan kesehatan. Jurnal Ilmu Pemertintahan Dan Sosial Politik, 1(2), 101-111.

Attaran, M. (2015). Moral education, habituation, and divine assistance in view of Ghazali. Journal of Research on Christian Education, 24(1), 43-51. https://doi.org/10.1080/10656219.2015.1008083

Doğanay, A. (2012). A curriculum framework for active democratic citizenship education. In M. Print \& D. Lange (Eds.), School, curriculum and civic education for building democratic citizens (pp. 19-39). Sense Publisher.

Hijriyani, Y. S., \& Machali, I. (2017). Pembelajaran holistik - integratif anak usia dini dengan pendekatan cashflow quadrant di RA Al Muttaqin Tasikmalaya. Al-Athfal : Jurnal Pendidikan Anak, 3(2), 119. https://doi.org/10.14421/al-athfal.2017.32-02

Kementerian Pendidikan dan Kebudayaan. (2017). Konsep dan pedoman penguatan pendidikan karakter. Kementerian Pendidikan dan Kebudayaan.

Lisnawati, S. (2016). The habituation of behavior as students' character reinforcement in global era. Jurnal Pendidikan Islam, 2(3), 413-428. https://doi.org/10.15575/jpi.v2i3.852

Menchik, J. (2014). Productive intolerance: godly nationalism in Indonesia. Comparative Studies in Society and History, 56(3), 591-621. https://doi.org/10.1017/s0010417514000267

Mujani, S., \& Liddle, R. W. (2004). Indonesia's approaching elections: politics, Islam, and public opinion. Journal of Democracy, 15(1), 109-123. https://doi.org/10.1353/jod.2004.0006

Permendikbud. (2018). Permendikbud RI No 20 Tahun 2018 Tentang Penguatan Pendidikan Karakter Pada satuan Pendidikan Formal. 8-12.

Salminati, I. (2017). Pembiasaan upacara bendera sebagai upaya pembentukan sikap nasionalisme siswa. Jurnal Kewarganegaraan, $1(1)$, 8-11. https://journal.upy.ac.id/index.php/pkn/article/view/877 
Syifa Siti Aulia, Dikdik Baehaqi Arif, Idham Sofihara, Astika Pungki Utami, Laelaturrohmah, Iqbal Arpannudin. Nationalist character at Muhammadiyah school

Sulistiyono, S. T. (2018). Nasionalisme, negara-bangsa, dan Integrasi Nasional Indonesia: Masih Perlukah? Jurnal Sejarah Citra Lekha, 3(1), 3-12.

Tilaar. (2007). Mengindonesia "Etnisitas dan identitas bangsa Indonesia." Rineka Cipta. 